\title{
Front Porch, Small House: A Longitudinal Study of Team and University Identification Among Incoming Students at a Division III University
}

\author{
Matthew Katz \\ University of Massachusetts Amherst \\ Marlene A. Dixon \\ Texas A\&M University \\ Bob Heere \\ University of South Carolina \\ Jordan R. Bass \\ University of Kansas
}

\begin{abstract}
In this longitudinal study, the authors examined the relationship between team identification and university identification for 37 incoming college first year students at a National Collegiate Athletic Association (NCAA) Division III institution. After collecting four waves of data from the same participants over the course of two years, the authors utilized growth curve analysis to examine the development and trajectories of the students' levels of identification with both the university and the intercollegiate sport teams. Furthermore, the authors empirically measured if identifying with the athletic teams on campus explained any variance in one's identification with the larger university. Finally, this study was explicitly conducted within the context of a Division III institution to increase understanding of the social value of Division III athletics for students not directly participating as student-athletes. The presented findings provide a longitudinal account of the psychological and social value of Division III sport teams in terms of building a stronger connection between new students and the larger university.
\end{abstract}

Keywords: team identification, university identification, Division III Athletics, longitudinal research, incoming students

\footnotetext{
Katz is with the Mark H. McCormack Department of Sport Management, University of Massachusetts, Amherst, Massachusetts. Dixon is with the Division of Sport Management, Texas A \& M University, College Station, Texas. Heere is with the College of Hospitality, Retail, and Sport Management, University of South Carolina, Columbia, South Carolina. Bass is with the Health, Sport, and Exercise Sciences Department, University of Kansas, Lawrence, Kansas. Address author correspondence to Matthew Katz at mkatz@isenberg.umass.edu.
} 
The role of intercollegiate athletics as the "front porch" for institutions of higher learning has been examined extensively at the Division I level (Bass, Schaeperkoetter, \& Bunds, 2015), but far less within Division III. With upwards of 450 participating institutions, Division III represents the largest NCAA division, yet the impact of athletics at the Division III level receives less academic attention than its Division I counterpart. And while the commercial interest and financial dedication of Division I programs dwarf those typically found in Division III, an educational institution's commitment to participate in Division III athletics nonetheless represents a substantial dedication of resources. In 2014, the median total expense for a Division III athletics program was roughly $\$ 3.4$ million, with some institutions spending upwards of $\$ 7$ million annually (Fulks, 2015). Given that type of financial commitment, colleges and universities undoubtedly expect a return on their investment in terms of enhancing the university as a whole.

Much of the academic research dedicated to the impacts of intercollegiate sport and the front porch phenomenon focuses explicitly on "big-time" college sport. From impacting visibility to notoriety to admission rates, the discourse on intercollegiate sport typically begins with the alleged economic impact of Division I sports (e.g., Clotfelter, 2011; Pope \& Pope, 2014). Yet a more recent wave of academic research has suggested that big-time college sport may also play an important role in helping students develop a sense of attachment or identity with the larger university - which increases student retention and well-being (Clopton, 2008; Heere \& Katz, 2014; Katz \& Heere, 2016; Warner, Shapiro, Dixon, Ridinger, $\&$ Harrison, 2011). Framed within a student development lens, these scholars have argued that identifying with university athletic teams might represent an example of increased involvement (Astin, 1984), integration (Tinto, 1987), and/or sense of belonging (Strayhorn, 2012) with the larger campus community.

As budgets in higher education tighten and campus administrators turn towards business centric strategies to enhance student recruitment and retention, the value of sponsoring Division III athletics depends, in part, on the social impact that Division III sports can have on campus. When administrators are faced with budgeting decisions, better understanding the social value of sponsoring Division III athletics to the larger campus community may very well play a vital role in properly assessing the place of Division III sports on campus; a place that may extend beyond the student-athletes themselves to the broader campus context as well.

According to Eifling (2013) and Demirel (2013), understanding the impact of Division III sports requires looking beyond simple expenses and revenues. As they both noted, the financial incentive for sponsoring Division III sports centers on the tuition received from participating student-athletes. Since Division III does not allow athletic scholarships, participating student-athletes pay tuition similar to non-student-athletes. In the case of Hendrix College, Demirel (2013) reported the football team alone resulted in tuition revenue close to $\$ 2$ million annually.

Yet the impact of Division III athletics on the larger university may run deeper than increased tuition payments of student-athletes. In addition to recruiting students to campus in the first place, private colleges that make up the majority of Division III members can increase revenue by improving retention rates among current students in the general student population. Students who 
are involved with different aspects of campus (Astin, 1984), who feel integrated within the campus community (Tinto, 1987), and who feel a strong sense of belonging on campus (Strayhorn, 2012) are more likely to remain enrolled and ultimately graduate. If the presence of Division III athletics on campus can impact how students' feel towards the campus community, the value of sponsoring Division III athletics from a whole university perspective increases. To understand the value of Division III athletics, then, necessitates understanding the social impact of Division III athletics for the whole student body, not just student-athletes.

University of Pittsburgh athletic director Scott Barnes stated that college sports is "not the most important room in the house, but it is the most visible" (Longman, 2009, p. 1). Barnes' comment is consistent with the front porch notion of intercollegiate athletics commonly discussed among big-time college sports. That is, in these contexts, college presidents consistently tout that their successful sport programs, primarily men's football and basketball-are what donors and prospective students notice first about a university. This visibility is then utilized as the rationale for exorbitant spending on coaching salaries, facilities, and even international contests, such that the front porch is maintained well.

This perspective of athletics as the most visible room in the house may seem not to apply to smaller colleges who lack the same levels of media attention for athletic programs, and whose donors may not be as directly tied to athletics. However, within the setting of smaller educational settings, particularly Division III, we argue that athletics very much serve a "front porch" role, not necessarily because they increase the curb appeal of the house, but because athletics serve as a great welcoming and socializing place for new inhabitants. This role, in the Division III setting, although different may be equally valuable to the long term viability of the university, and critical to the retention of students. Thus, we explored to what extent college athletics in smaller institutions plays a role in socialization and contribution to a sense of community within the university.

The impact of this study is multi-faceted. As pressures mount on college and universities to increase both student retention and graduation rates from public officials and taxpayers alike (Bass et al., 2015; Crisp, Baker, Griffin, Lunsford, \& Pifer, 2017), the need to further understand the impact of Division III athletics on these institutional goals only grows. Though anecdotal claims of college athletics acting as a promotor of attitudes towards the university may be commonplace, they lack the empirical evaluation necessary to truly gauge the impact of Division III athletics in building positive sentiment towards the larger university by campus stakeholders. Thus, in this longitudinal study, we explored the growth trajectories of individual attitudes towards Division III athletic teams (i.e., team identification) and the larger university (i.e., university identification) and empirically test whether one's attitudes towards sport teams drives one's attitude towards the larger university by tracking a group of incoming freshman students over a two-year period. Through such an examination, the trajectories of team identification, university identification, and the extent to which changes in team identification drive changes in university identification can be empirically examined to provide novel insight for scholars and administrators alike with interests at the Division III level. 


\section{Literature Review}

The relationship between intercollegiate athletics and American institutions of learning is marked by a contentious rapport. Critics of the intercollegiate system highlight the financial dependence of most athletic programs on the operating budget of the university and the discrepancy between an institution's academic and athletic missions (Sperber, 2000). Yet intercollegiate sport remains a popular entity, both in terms of spectator attraction and the number of participating institutions. Advocates of the intercollegiate system claim a number of positive institutional benefits of intercollegiate sports, ranging from financial to social impacts. In his review of this literature, Clotfelter (2011) categorized four ways in which intercollegiate sport can potentially benefit the university: (a) encouraging more students to apply, (b) stimulating more charitable donations, (c) distracting alumni from noticing how different the values of the faculty are from their own, and (d) causing the state government to act more favorably toward the institution. Ultimately, Clotfelter (2011) found sufficient support only for the first claim, a finding echoed by recent research by Pope and Pope $(2009 ; 2014)$. Yet, what was missing from his review was to what extent intercollegiate sport provides a source of organizational identity with the university (Katz \& Heere, 2016), and how that sense of university identity contributes to retention.

Clotfelter's (2011) work is illustrative of the larger research on the relationship between college sport and institutions of higher learning for two reasons. First, the bulk of researchers have focused primarily on the direct economic impact of college sport, as Goff (2000) found the "profitability issue" of college sports was the most popular research topic in the field. Secondly, most of the research focuses exclusively on "big-time" college sports. From Clotfelter's (2011) Big-Time Sports in American Universities to Sperber's (2000) Beer and Circus: How Big-Time College Sports is Crippling Undergraduate Education, most of the prominent research in this field intentionally focuses only on big-time college sport. As a result, we argue that additional research is needed to better understand the social impact of college sports, particularly in settings outside of big time intercollegiate athletics.

\section{Front Porch: College Sports and the Campus Community}

Though studies of profitability and economic impact permeate the research on college sport (Goff, 2000), a growing wave of researchers have begun empirically measuring the social impact of intercollegiate sports on college campuses (e.g., Wann \& Robinson, 2002). Clopton (2008), for instance, found a significant relationship between a students' perceived sense of community on campus and the students' psychological connection with athletic teams. In a similar study, Clopton and Finch (2008) found that a students' attachment to college athletic teams paralleled a significant impact in perceived levels of social capital on campus. Based on these studies, the impact of college sports extended beyond direct revenue into the social realm of college campuses. To build upon the work of Clopton and colleagues, scholars isolated instances of newly formed college sport teams to test if a new team changes feelings of community on campus. In exactly such a setting, 
Warner et al. (2011) did not find evidence that a new college football team increased sense of community among students, while Heere and Katz (2014) did find that a new team significantly increased how university stakeholders identified with the university itself. In a recent longitudinal study of the issue, Katz and Heere (2016) found that over a three-year period identifying with a newly formed college football team significantly predicted one's identification with the larger university.

Scholars in higher education have developed a number of theories in attempts to understand why some students persist in college while others do not. Based on Pascarella and Terenzini's (2005) review of the higher education literature, one of the most salient factors in explaining student persistence and retention is the prominence of engagement on campus. Whether engagement is conceptualized as a matter of becoming "involved" based on Astin's (1984) work or "integrated" based on Tinto's (1987) research, the importance of students finding engagement on campus is substantial. As Pascarella and Terenzini (2005) concluded, "The evidence consistently indicates that academic and social involvement in whatever form (but some more than others) exert statistically significant and positive net influences on student persistence" (p. 440). The foundational assumption of college sports positively impacting students on campus is that developing a psychological attachment with sport teams can serve as such a type of engagement activity that increases one's association with the university. In the present study, the authors used social identity as a proxy for one's attachment with the larger university (Carlson, Suter, \& Brown, 2008; Katz \& Heere, 2016) to empirically test if a student's connection with sport teams affected their attachment with the university.

\section{Small House: Division III Sports}

Since the NCAA restructured into a three-division model in 1973 (Katz \& Seifried, 2014), the impact of the NCAA's "smallest" division has remained overshadowed by academic and commercial studies over the role of big-time college sport (Katz \& Clopton, 2014). This is not to say that scholars have entirely overlooked Division III as a research setting, as scholars have produced a wide spectrum of topical studies within the context of Division III athletics. For example, previous studies of the Division III setting include such topics as managing employee diversity (Fink, Pastore, \& Riemer, 2003), educational values (Bowen \& Levin, 2003; Shulman \& Bowen, 2002), administrator core values (Cooper \& Weight, 2012), factors of success (Katz, Pfleegor, Schaeperkoetter, \& Bass, 2015; Sparvero \& Warner, 2013), as well as institutional theory and divisional affiliation (Smith, Williams, Soebbing, \& Washington, 2013). Despite these earlier studies, Division III remains understudied as compared to big-time college sports and more importantly for the current study, previous research has not adequately examined the social impact of Division III sports on college campuses.

Katz and Clopton (2014) provided perhaps the only study to explicitly examine the social impact of Division III athletics on campus stakeholders. More specifically, Katz and Clopton (2014) examined if Division III athletic programs serve as social anchors between the university and various stakeholder groups (i.e., students, community members). While they found little evidence that identifying with the 
intercollegiate sport teams contributed to students' report levels of social capital, they did find that Division III athletics can serve as a conduit for connecting the students with the surrounding community in which the university was located. In the current study, we offered an extension of Katz and Clopton's (2014) approach and findings through a number of methodological modifications. First, the present study used a multidimensional identification scale that provides more informative insight into the social identity process than a unidimensional scale (Heere, Walker, Yoshida, Ko, Jordan, and James, 2011; Katz \& Heere, 2016; Lock, Funk, Doyle, $\&$ McDonald, 2014). And secondly, we utilized a study design that allowed for a longitudinal examination of how identifying with Division III athletic teams impacts ones identification with the larger university.

Unlike the cross-sectional approach used by Katz and Clopton (2014), the longitudinal approached used in the present research endeavor allowed for a true measure of change (Singer \& Willet, 2003) and questions of prediction to be examined. While cross-sectional studies can claim a relationship between feelings of connectedness with college sport teams and the university, it is only through a longitudinal approach that one can surmise how a connection to college sport teams predict how an individual identifies with the larger university. Based on these methodological improvements, the present offers a more detailed examination of the social impact of Division III athletics on college campuses.

In many ways, this study was designed to emulate the findings of Katz and Heere (2016) but specifically within the context of Division III athletics and with a number of other changes. Katz and Heere (2016), like Warner et al. (2011) before them, examined the social effects of a newly formed college football team. Using a longitudinal design, Katz and Heere (2016) found the formation of a new football team did significantly alter how university stakeholders identified with the larger university. In other words, the social impact of that newly formed football team proved substantial enough to change the ways university stakeholders felt towards the larger university. In the present study, we followed a similar research approach, but with a Division III setting intentionally selected to better understand the role of intercollegiate athletics at the "lower" level of the NCAA. And rather than using a combination of faculty, alumni, and students, the present study used only two cohorts of incoming students - to truly capture the identification processes for new students at the university. By focusing explicitly on new students, our results should be more valuable in terms of understanding involvement, integration, sense of belonging, and ultimately retention for new students.

As a result of this literature review and our overarching research objective, the current study was guided specifically by the following research questions:

RQ1: For incoming students at Division III institutions, how do the different dimensions of team identity change over time?

RQ2: For incoming students at Division III institutions, how do the different dimensions of university identity change over time?

RQ3: For incoming students at Division III institutions, to what extent can the development of team identification predict changes in the development of university identification? 


\section{Method}

\section{Data Collection}

The data collection for this longitudinal study occurred over a two-year period beginning with incoming students at a small, private, Division III institution in the southwestern region of the United States. The college enrolls approximately 2,300 students and sponsors over 15 varsity sports, including football. After receiving permission from college administrators, two freshman orientation groups were selected as potential participants for this study. Orientation groups typically consist of 15-20 students and the two groups targeted for this study were not created on any specific criteria. The 15-20 students in the two groups did not share a common major, hometown, extracurricular activity, or career aspiration.

Two weeks into the students' first semester on campus, an email was sent to the 19 first-year students in Group 1 and the 18 students in Group 2 explaining the nature of the study, requesting their participation in the study, and giving students the ability to option out of the study. Two weeks later, the researchers sent another email to the students with a link for an electronic survey for the study. Follow-up emails were sent one-week later to participants who did not respond to the initial request. In the first-wave of data collection, 33 of the 37 potential participants completed the survey for a response rate of $89.18 \%$. Based on the success of the first-wave of data collection, the same protocol was used for the second, third, and fourth-waves of data collection as well. These collections occurred in subsequent semesters; each time the survey was one month into the semester. Response rates differed slightly for each wave, but over the course of the four waves of data collection, 101 usable surveys were collected.

The 33 participants in this study were largely representative of the student body of the research setting, though there was an overrepresentation of female students. Specifically, 20 females and 13 males participated in the study, which represents a slight higher percentage of female participants $(60.06 \%)$ than the larger student body $(55 \%)$. Ten of the students reported participating on varsity athletic teams, a percentage $(30.30 \%)$ nearly identical to the larger campus population (30\%). All participants were first-year students at the beginning of the data collection process. The only sampling criteria were a participant was entering their first-semester and they were at least 18 years old. Other than these restrictions, all members of the two randomly selected orientation groups were eligible for participation.

Before discussing the instrumentation used in this study, we would like to discuss sample size and longitudinal data analysis. According to Singer and Willet (2003), there are no formal rules or procedures for sample sizes in growth curve analysis. Rather, growth curve analysis studies must meet the following three requirements: 1) three or more waves of data; 2) an outcome whose value changes over time; and 3) a sensible metric for clocking time. In their discussion of when and how to use growth curve analysis, Singer and Willet (2003) never provide a minimum sample size but rather highlight a number of influential studies who successfully used small samples. Huttenlocher, Haight, Bryk, Seltzer, and Lyons (1991), for instance, wrote an influential paper on vocabulary growth among children using a sample size of 22. In another prominent example, Svartberg, Seltzer, Stiles, and Khoo (1995) produced a growth curve analysis study of short-term dynamic 
psychotherapy with a sample size of only 15. And Tivnan (1980) also explored longitudinal changes in elementary aged children with a sample size of 17 . With sample size in this range, Singer and Willet (2003) state that growth curve analyses must treat time as a linear concept and refrain from examining group differences within the model. Studies of individual change with sample sizes as low as 15 , then, are appropriate for growth curve analysis when the other requirements of growth curve analysis are met.

\section{Instrumentation}

Each of the four waves of data collection utilized the same survey and instrumentation to measure the participants' levels of identification with both the university and the Division III athletic team. A version of the Team*ID scale proposed by Heere and James (2007) and later modified by Heere et al. (2011) was used. The authors intentionally used a multidimensional scale over a unidimensional scale because it would allow for a more detailed and in-depth description of the change process for the participants' university and team identifications. The Team*ID scale consists of six different dimensions of identification: (a) private evaluation, (b) public evaluation, (c) sense of interdependence, (d) interconnection of self, (e) behavioral involvements, and (f) cognitive awareness. Each of these dimensions has been tested within the context of college students and college sport fans, hence we felt it was an appropriate measure given our stated purposes. A total of 19 items were used to measure a participants' team identification and the same 19 items, with different wording, were used to measure university identification (Table 1). We also collected basic demographic information about each participant.

\section{Data Analysis}

To analyze the longitudinal change in team and university identification for the participants of this study, a growth curve analysis was used to examine the data. Growth curve analysis is a multilevel approach to examining a study that models the shapes of individual trajectories over time. It examines the variance in these trajectories as a systematic result of occasion-level and subject-level covariates while also accounting for random variation by subject (Singer \& Willet, 2003). Longitudinal techniques are needed to truly study change, since cross-sectional approaches cannot adequately address questions of development or change (Singer $\&$ Willet, 2003). A pre-test versus post-test examination, such as the one used by Warner et al., (2011), offers only an association between initial measurements and later measurements; they do not actually measure the trajectory of change for a variable and are likely to be an unreliable estimator of change (Singer \& Willet, 2003).

Growth curve analysis provides an appropriate framework for investigating change over time when three conditions (Singer \& Willet, 2003) are met: (a) there are three or more waves of data, (b) an outcome whose value changes systematically over time, and (c) a sensible metric for clocking time. The authors used four waves of data, thus satisfying the first prerequisite condition. The selected outcomes, both team and university identification, represent a metric in which the outcome scores are equitable over time. An identification score during one wave of data collection is identical to the same score in a subsequent wave, and the metric, validity, and 
Table 1: Team*ID Scale (Heere et al., 2011)

\begin{tabular}{ll}
\hline Construct & Description \\
\hline Private Evaluation & The attitude that an individual has personally towards the \\
group & 1. I feel good about being a fan of my team \\
2. In general, I am glad to be a fan of my team & 3. I am proud to think of myself as a fan of my team \\
The perceived attitude of non-members towards the group \\
by the individual \\
1. Overall, my team is viewed positively by others \\
2. In general, others respect my team \\
3ublic Evaluation \\
team \\
The degree to which the individual feels the group is a part \\
of him/herself \\
1. When someone criticizes my team, it feels like a per- \\
sonal insult \\
2. In general, being associated with my team is an impor- \\
tant part of my self-image \\
3. When someone compliments my team, it feels like a \\
personal compliment
\end{tabular}


precision of our outcomes were safeguarded by the data collection and instrumental method used in the study. Finally, because the participants were students on a particular college campus, the standard metric for defining time in college settings was used: semesters. Each of the four waves of data collection occurred at roughly the same point in the semester, thus making a semester a sensible metric for clocking time.

As a Level 1 model, the authors calculated unconditional growth models that represented each participants' dimensions of identification change trajectories to examine RQ1 and RQ2. For the Level 2 model, the authors calculated conditional growth models that examined if the included time-invariance characteristics of the individual predicts individual changes in trajectory in order to examine RQ3. In other words, the unconditional growth models change over time for each individual dimension of team and university identity. The conditional growth models were run for each individual dimension of university identification by including the team identification dimensions with the model; the results illustrate the extent to which changes in team identification predict changes in university identification. By including the team identification dimensions within the conditional growth models for each university identification dimensions, Pseudo- $R^{2}$ statistics were calculated that measure the proportional reduction in residual variance as additional predictors were included in the models (Singer \& Willet, 2003). For RQ3, the Pseudo- $R^{2}$ represents how team identification trajectories predict changes in university identification.

\section{Results}

The results from the unconditional growth curve models are presented for each dimension of team identification and university identification in both Table 2 and Table 3. In Table 2, the intercepts and slopes of the dimensions are presented with a single statistic for the entire four waves of data collected. In other words, Table 2 represents the slope of individual dimensions over the entirety of the research endeavor. In Table 3, the authors present the slopes of each individual dimensions between each of the data collections. Table 3 provides more specific detail on the changes in identification dimensions during each semester.

In addressing RQ1, there were noteworthy differences in the starting points (intercepts) of the participants as they entered the university. Notably, the participating students reported the highest intercept in their private evaluation of the team (5.718) followed by publication evaluation (5.257), while the lowest intercepts were for interconnection of self (4.150) and sense of interdependence (4.150). Looking at the slopes found in Table 2, all of the dimensions of team identity reported a negative slope over the two-year period, with behavioral involvement $(B=-.156, p$ $=.05)$, cognitive awareness $(B=-.132, p=.04)$, and private evaluation $(B=.2052$, $p=.003)$ all significant at the .05 level or lower. Both interconnection of self $(B=$ $-.1393, p=.09)$ and sense of interdependence $(B=-.1384, p=.09)$ were above the .05 cutoff point typically associated with significant values but within the range of significance suggested by Singer and Willet (2003) for interpreting growth curve analysis. The results displayed in Table 3 further illustrate the trajectories for the dimensions of team identity, signifying that the significant decreases all occurred between the third and fourth data collections. Sense of interdependence recorded 


\section{Table 2. Summary of Growth Curve Analysis for Individual} Dimensions for Entirety of Four Waves of Data Collection

\begin{tabular}{lllll}
\hline Variable & Intercept & Slope & SE & P \\
\hline BEHT & 5.195 & -.1564 & .0808 & $.05^{*}$ \\
COGT & 4.683 & -.1321 & .0648 & $.04^{*}$ \\
INTT & 4.150 & -.1393 & .0822 & .09 \\
PREVT & 5.718 & -.2052 & .0684 & $.003^{* *}$ \\
PUBT & 5.257 & -.0618 & .0869 & .47 \\
SOIT & 4.150 & -.1393 & .0822 & .09 \\
\hline
\end{tabular}

\begin{tabular}{lllll}
\hline Variable & Intercept & Slope & SE & P \\
\hline BEHU & 5.830 & -.0648 & .1041 & .534 \\
COGU & 4.983 & .0519 & .0867 & .549 \\
INTU & 5.401 & -.0729 & .1116 & .514 \\
PREVU & 6.313 & -.1270 & .1146 & .268 \\
PUBU & 6.168 & -.154 & .1151 & .181 \\
SOIU & 5.638 & -.0499 & .0982 & .611 \\
\hline
\end{tabular}

$*$ values significant at the .05 level $* *$ values significant at the .01 level $* * *$ values significant at the .001 level

the largest decrease $(B=-.7864, p=.005)$ from the third point to the final data collection.

While the results in Table 2 may suggest a negative slope over the course of two years, Table 3 indicates the dimensions of team identity did not change significantly during the first two waves of data collection, and mostly significantly decreased only during the last wave of data collection. It should also be noted that public evaluation of team was the only dimension that did not significantly decrease (or change at all) during the study. None of the dimensions showed any significant increase at any point during the study, as the starting intercepts reflected the highest scores for all dimensions of team identification.

The results for RQ2 are relatively straightforward-none of the dimensions of university identification changed significantly throughout the two years of data collection, as shown in Table 2. When looking at the change between specific data collections, there were only two significant changes: cognitive awareness increased $(B=.1592, p=.05)$ between data collection 1 and 2; public evaluation significantly decreased $(B=-.4887, p=.05)$ between data collection 2 and 3 . Neither of these changes were substantial enough to lead to a significant change overall in those dimensions.

The intercepts presented for university identification are also found in Table 2. Private evaluation (6.313) and public evaluation (6.168) had the highest starting values, while cognitive awareness had the lowest. The intercepts for university 


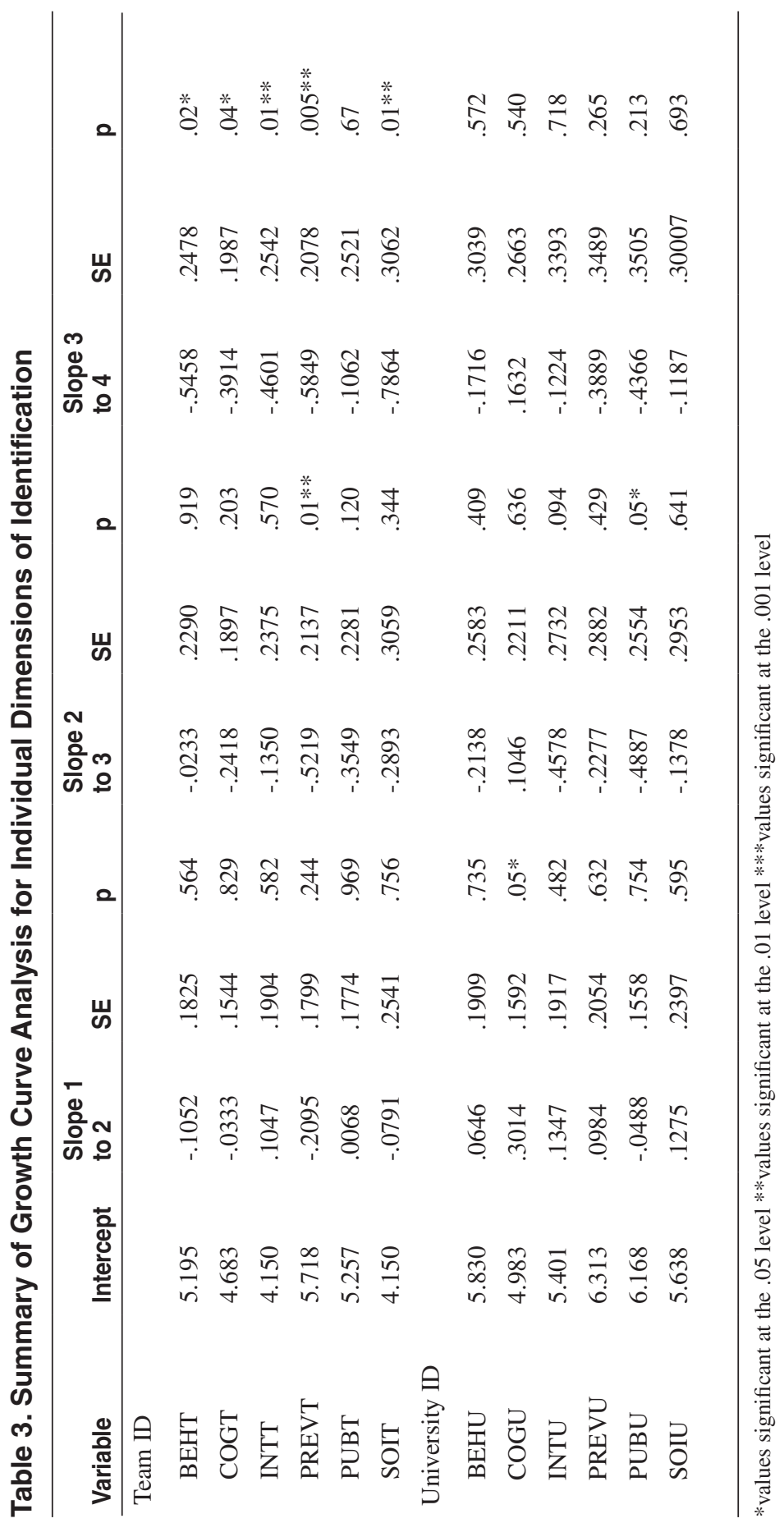




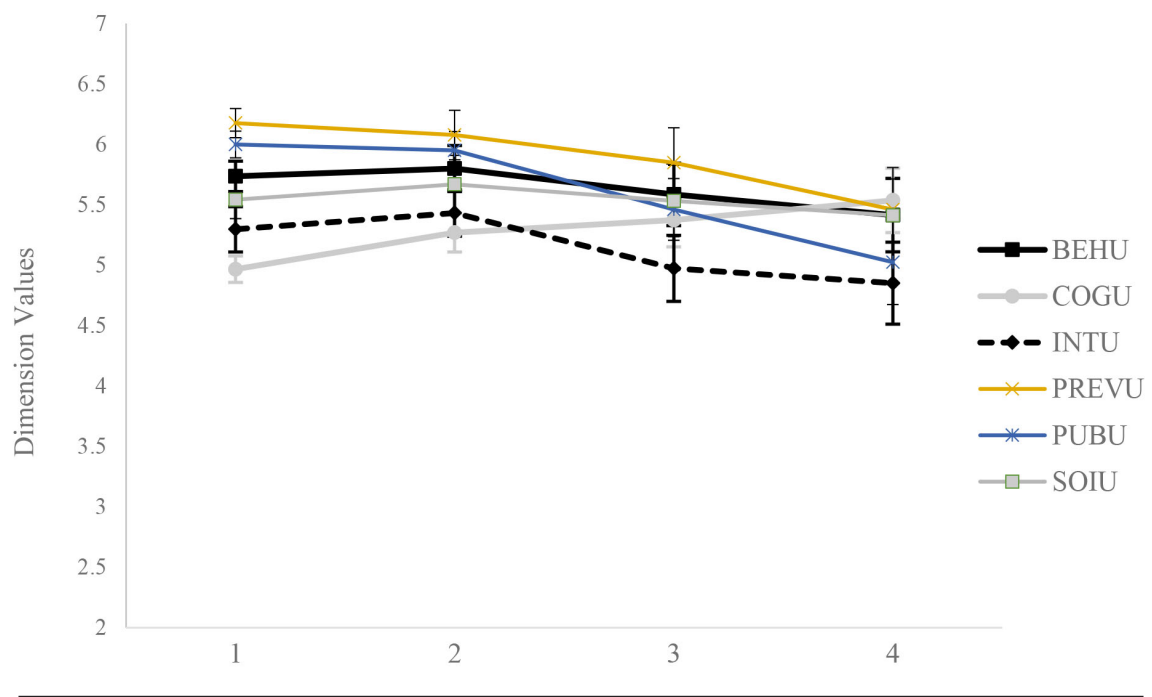

Figure 1: Longitudinal Development of University Identity Dimensions

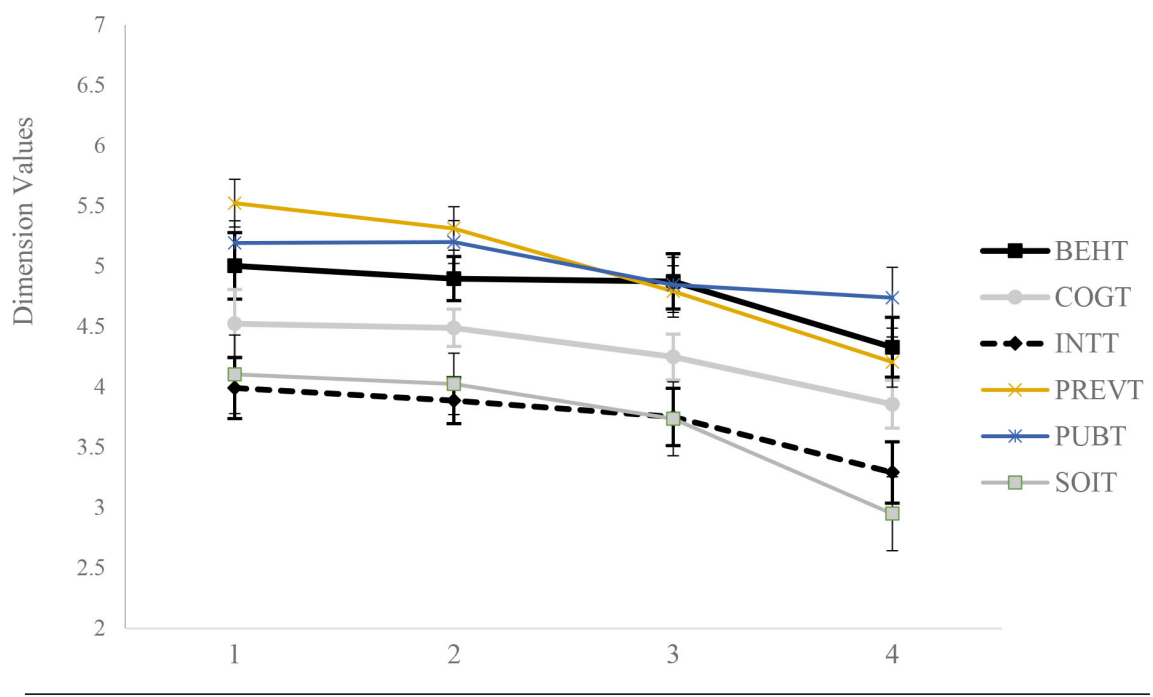

Figure 2: Longitudinal Development of Team Identification Dimensions

identification were higher than the same dimension of team identification for all dimensions, with the largest difference between university identification and team identification in sense of interdependence (1.488) followed by interconnection of self (1.251).

For RQ3, the pseudo- $R^{2}$ statistics presented in Table 4 are based on the conditional growth model that examined the association between predictors and patterns 


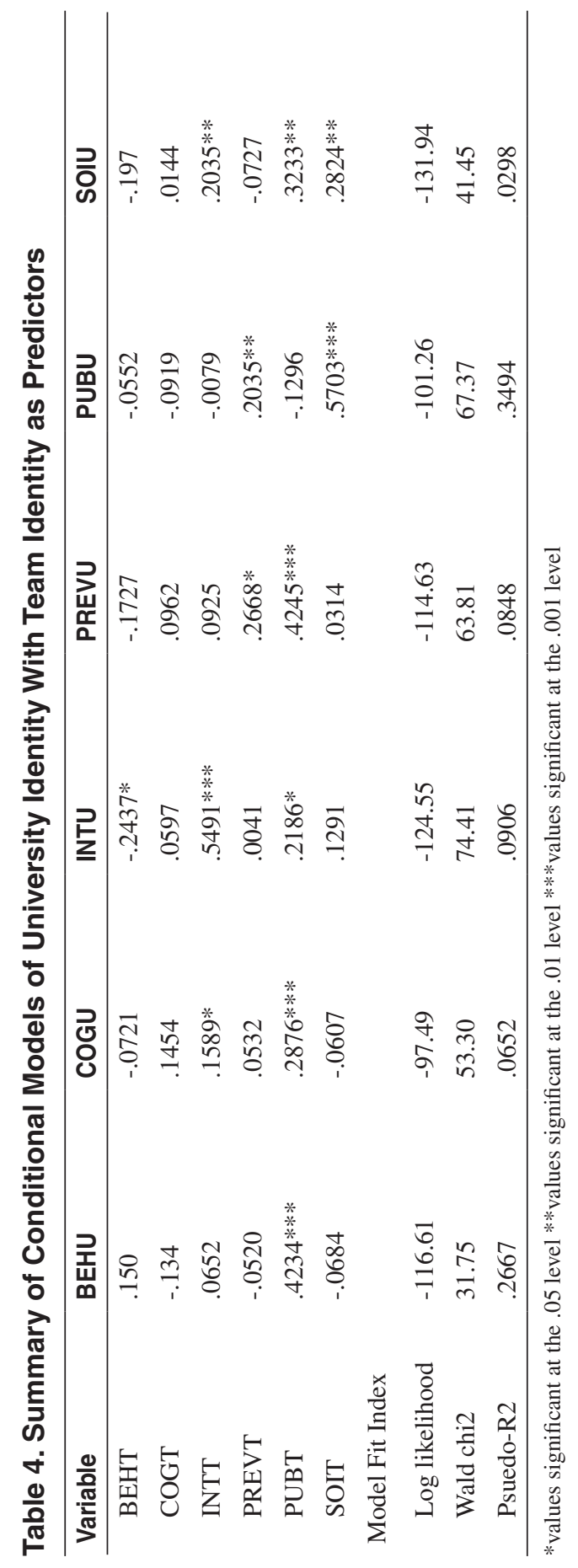


of change. The pseudo- $R^{2}$ statistic represents the proportional reduction in residual variance resulting from including additional predictors in the model. For example, the trajectories of team identification dimensions explained roughly $26.67 \%$ of the variance in one's trajectory for behavioral involvement with the university. The largest pseudo- $R^{2}$ was for one's public evaluation of the university, where $34.94 \%$ of the variance was explained by the dimensions of team identification. The dimensions of team identification had very little impact on cognitive awareness of the university $(6.52 \%)$, interconnection of self $(9.06 \%)$, private evaluation $(8.48 \%)$, and sense of interdependence $(2.98 \%)$. Even though the university identification dimensions did not significantly change over the course of the study, the trajectories of team identification dimensions still had a significant impact on several of the university identification dimensions.

\section{Discussion}

For the 33 participating students in this study, the Division III athletics program at their university did serve as a front porch for the larger university in terms of their integration and socialization into the university. While Division III sports may lack the visibility and notoriety that some athletic programs provide at the Division I level, the intercollegiate teams on campus in this study served a vital role as a front porch in terms of giving new students an early point of attachment on campus. In terms of understanding the social impact and value of Division III athletics, this is a noteworthy finding. Nearly one-third of college students change institutions at some point prior to earning their degrees (Hossler et al., 2012), and the greatest number of departures occur during the first year (Rausch \& Hamilton, 2006) - thus, providing a point of attachment during the early moments of a student's tenure on campus is a vital role and certainly contributes to the social (if not also the economic) impact of Division III sports.

Compared with the findings from Heere et al.'s (2011) study of students at "big-time" college sport institutions, the participants in the present study reported much higher scores for public evaluation, interconnection of self, sense of interdependence, and behavioral involvement with the sport teams. This was a surprising finding, and the second noteworthy takeaway from the present analysis. The media attention and commercial interest in big-time college sport undoubtedly supersedes that associated with Division III athletics, yet when the participants arrived on campus they reported higher levels of identification with the college sport teams than the participants in Heere et al. (2011). Before discussing the slopes or the relationships between team and university identification, the initial intercepts portrayed a strong psychological relationship between incoming students and Division III athletic teams. For each of the dimensions of team identification, the reported intercept was above 4.0-suggesting that participants agreed with the items. Rarely does one hear about the impact of Division III sports on non-athletes on campus; yet this intercept suggests students enter campus with a strong sense of identification with sport teams. This was perhaps the most surprising finding of the study.

Division III athletics largely lacks the media coverage and national attention of Division I institutions. As a result, it is often assumed that "fans" of Division III schools are limited to those playing the sport and the friends or family of those playing (Robinson, 2010). But the team identification intercepts present a 
different narrative, one where students arrive on campus with an established sense of identification towards the athletic teams. In terms of understanding the social impact of Division III sports, that discussion begins with the attitudes incoming students have as they arrive on campus. Even without the luxury of lifelong fans or, presumably, a history of attendance at games prior to enrolling in the school, the incoming students in this study arrived on campus with strong levels of identification towards the university teams. Within the Division III setting, we found evidence that incoming students already identify with the mystique of intercollegiate athletics and exhibit an expectation to associate with the teams on campus. Perhaps this is due to intimate nature and size of the campus, one that is reminiscent of Division III athletics as a whole. Since in this type of educational setting the participants likely were in classes, dormitories, and other social settings with student-athletes. Schaeperkoetter, Bass, and Gordon (2015) found in small college athletics that student-athletes seemed representative of the general student body, which might explain the strong initial identification with the teams by non-athletes.

Though the high intercept levels of team identification suggest a salient role of sport teams on the social fabric of campus, the newcomers' level of identification with the intercollegiate teams on campus appeared to lose its luster as students became more familiar with campus. The negative slopes for all dimensions of team identification is the third notable finding, suggesting that the newcomers in this study actually decreased their level of identification following their third semester on campus. By this time, the athletic teams on campus stopped serving as the most visible point of attachment with the larger university-the new students were no longer viewing only the front porch of the university as they gained access to the rest of the university. Students typically become more involved in other campus activities, ranging from Greek Life to service organizations to interest-based clubs during this time period (Astin, 1984), after the initial shock of adjusting to their college routine settles following the first year experience.

While the decrease in team identification may suggest a lesser importance of Division III sports within the larger campus community, we feel this conclusion is shortsighted. As newcomers become oriented in campus life, the community transitions from "imagined" towards something more tangible. Anderson (1983) suggested in larger communities, or imagined communities that individuals can only identify with the overarching collective through smaller groups. Sport, as Hobsbawn (1990) acknowledged, can represent exactly such a smaller and more tangible group: "The imagined community of millions seem more real as a team of eleven named people" (p. 143). In the present research setting, sport serves as a tangible initial attachment. Then, as the new students became more acclimated and involved in the campus community, they replaced the front porch with other components of campus that also became more tangible over time.

As much as the negative team identification slopes signal a decrease in psychological attachment with the sport teams, they may very well indicate increased attachment with other aspects of the campus community. Further justifying such a notion, the fourth noteworthy finding from the growth curve analysis is that university identification did not change over the two-year period. From the perspective of the athletics department, that suggests as newcomers decreased their attachment with athletics they found some other means of fulfilling the need to connect with the larger university. Without some type of substitute, we would have found decreased 
university identification levels coinciding with the decreased team identification levels - but this was not the case. Again, this does not diminish the social value of Division III sports; rather it magnifies the social value of sponsoring Division III for the benefit of the larger campus community. Up until the point when new students find tangible ways to connect with the campus and other students, the intercollegiate athletic teams provide a necessary means of building community.

In analyzing the trajectories of university identification, it was somewhat surprising that university identification remained constant, rather than increase as students became more integrated with the campus community. Based on existing theory in identity negotiation and student retention, we expected an individual's identification with the university to increase over time. Perhaps some students would be disappointed with their experiences on campus, while others became more engaged with the university and increased their attachment to the university. But nonetheless, the dimensions of university identification remained constant. Katz and Heere (2016) wrote that new identities were more volatile since attitudes had not been previously formed and cemented. Yet for the participants in this study, there was very little change in their levels of identification with the university from their first month on campus to their fourth semester.

The lack of significant change in university identification may indicate that students in this setting adjusted very quickly to the campus community and were socialized incredibly early in the tenures on campus. Rather than slowly growing their levels of identification with the university over the course of several semesters, as one could presume they would, new students entered the university with heightened levels of identification already formed. Reflecting on the initial scores for the participants in this study, many of the dimensions of university identification were much higher than the scores reported by Heere et al. (2011), notably interconnection of self, sense of interdependence, and behavioral involvement with the university. Such discrepancies might make sense given the smaller campus size of the research setting, and provide support to perhaps another difference between Division III sports and their big-time counterparts. In smaller campus communities, identifying with the athletic teams appears less abstract - the players on the field, for example, are less of a distant spectacle and more an intimate part of students' everyday lives, thus providing an easier outlet to identify initially. The constant nature of university identification represents the fourth noteworthy finding from our growth curve analysis.

The results from RQ3 deserve attention here but must be approached with caution. The relatively high pseudo- $R^{2}$ for both public evaluation of the university and behavioral involvement with the university suggest that identifying with sport teams at the Division III level does predict how a student identifies with the larger university. These pseudo- $R^{2}$ are actually larger than any of the pseudo- $R^{2}$ found in Katz and Heere's (2016) study of the new football team. Yet because the university identification dimensions did not significantly change for the participants, we must be careful not to overstate the results of the conditional growth models. For the participants in this study, the trajectories of team identification during their first two years in college explained roughly $25 \%$ of change in their behavioral involvement with the university - though the change in behavioral involvement was not necessarily substantial. The absolute value of the pseudo- $R^{2}$ should be interpreted with caution, but the overall relationship in these particular dimensions is supported 
by the analysis. A new students' development of behavioral involvement with the university was significantly predicted by the development of the identification with the sport team-suggesting a new value and social benefit for Division III sports on campus.

From a theoretical standpoint, the presented results build on the existing discourse regarding the link between team attachment and university outcomes. The current endeavors echoes the findings of Wann and Robinson (2002), Clopton (2008), and Heere and Katz (2014) that identifying with sport teams on campus has a relationship with one's psychological feelings towards the university. Interestingly, each of these studies took place within very different settings — ranging from a newly formed Division I football team to the present Division III setting-yet each found a similar relationship. The present study also extends on those findings, however, by including a longitudinal element to the study design which allows for conclusions about predicting, not merely association. In that regard, we believe this study more strongly confirms the relationship between team identification and university attachment by showing that changes in team identification actually drive changes in feelings towards the university.

Furthermore, in many ways the present study was designed to build upon Katz and Clopton's (2014) examination of Division III athletics as community social anchors. By implementing a longitudinal methodology and incorporating a multidimensional measure of identification, the findings were vastly different as related to students. Katz and Clopton (2014) found that university identity was the overwhelming social anchor for students, yet their methodology prevented any discussion of what drove that initial university identity in the first place. Theoretically, it may be the case that team identification initially drove that heightened sense of university identification which scored as a social anchor for the larger student body. Team identity showed no contribution to social capital in Katz and Clopton's (2014) study, but we argue based on the current study that team identification may have developed the university identification that ultimately served as a social anchor.

Additionally, the high intercepts of team identification scores suggest that theoretically identifying with a sport team may be an example of campus integration (Tinto, 1987) and involvement (Astin, 1984). Scholars in higher education have questioned whether all involvement on campus is good involvement (Mangold, Bean, \& Adams, 2003) or whether all forms of involvement are equally beneficial. We argue that sport fandom, as a means of identifying with an anchor on campus, is linked theoretically with other forms of involvement and integration. And though studies of retention rarely mentioned sports outside of explicitly examining studentathletes (Pascarella and Terenzini, 2005), perhaps the theoretical interpretation of engagement and involvement activities need be extended to include sport fandom or team identification more generally.

It is necessary to address a number of limitations to the present study. First, the data was collected from participants at a single Division III institution. Division III schools represent an extensive spectrum of different institutional characteristics ranging from private to public, large institutions to extremely small, and small athletic budgets to substantial ones. As Katz et al. (2015) illustrated, there is a substantial gap in Division III athletic success between those who typically "win" at the Division level (e.g., academically elite and large public institutions) and those institutions that rarely win (e.g., lower budget regional schools). The setting used 
in this study was a college with success both athletically and academically. The college has a strong academic rating regionally and nationally, and several athletic teams typically compete for conference and national championships. The athletic and academic success of the college may have impacted the results of this study. And the research setting did sponsor football-a sport not found in all Division III institutions. Though we cannot say with any certainty the particular role that football played in the experiences of the study participants, it is worth noting that the research was conducted within a school that sponsored football. Additionally, because we measured team identification through a general attachment with all of the university sport teams, we cannot comment on which athletic teams were higher or more impactful than others. A future study might differentiate between attachment to individual teams on campus, noting potential relationships with specific sports based on individual characteristics of the student (i.e., gender, race) or if any differences occur between traditionally successful teams and less successful teams.

Second, while the use of four waves of data collection represents a marked improvement upon similar studies of college sport on campus, the authors stopped tracking the trajectories of team and university identification after the participants' first two years. Perhaps a four-year study of student identity development would paint a more thorough picture of the changes in social identities for Division III students. Future studies might also consider collecting data from students after graduation. If one of the alleged benefits of college athletics is alumni donations and support (Clotfelter, 2011), a longitudinal study of students that extends into the time as alumni might provide additional insight into that component of the intercollegiate sport.

Third, while the sample sized used this study was consistent with previous growth curve analysis research, a larger sample size could allow for a more nuanced exploration. Specifically, a future study might consider examining group differences between student-athletes and non-athletes within the intercepts and trajectories of team and university identification. Because student-athletes represent roughly $30 \%$ of the campus population, examining non-athletes separately may isolate the social impact of Division III athletics specifically for non-athletes. Finally, if future scholars sought to conduct a similar study of incoming college freshman, we recommend including a point " 0 " before students arrive on campus. The participants' first semester was used as the intercept for the trajectories of their identification, but future studies might consider measuring an intercept even before the student arrives on campus.

\section{Conclusion}

As the largest of the NCAA's divisions in terms of participating institutions and student-athletes, the larger goal of this research endeavor was to further explore the social impact of Division III sports on college campuses. By isolating a single Division III institution and tracking two cohorts of incoming students over a twoyear period, we were able to empirically examine the trajectories of both team and university identification among the participants. Moreover, the conditional growth models measured the extent to which changes in the development of team identification drove changes in how the participants identified with the university. In a general sense, the results of our analysis suggested that Division III athletics 
played a prominent role in helping new students initially identify with the larger university - that before students had the opportunity to engage with other aspects of campus, Division III sports served as a front porch in welcoming and socializing new students into the campus community.

According to Fulks (2015), the median expenses of Division III institutions were roughly $\$ 3$ million annually, and the Division III programs that compete for regional and national championships consistently spend far more than the average (Katz et al., 2015; Sparvero \& Warner, 2013). While \$3 million annually pales in comparison to the budgets of big-time college sport programs, it nonetheless represents a substantial institutional investment by the colleges and universities competing at the Division III level. From a practical standpoint, we offer a number of suggestions to ensure that investment is leveraged and its positive effect on campus is maximized by administrators of Division III institutions.

First, if campus administrators hope to use Division III athletics to impact students on campus beyond the student-athletes, our analysis suggests administrators are wise to act quickly. Incoming students arrived on campus with surprisingly high levels of team identification, suggesting a substantial psychological attachment to the teams. As a result, administrators can use the athletics program as focal points of social anchors for new students in the early days of their tenure on campus. Including events focused on the athletic teams, perhaps an orientation group attending a soccer game together or an organized class tailgate prior to first football games, during the initial socialization period may maximize the social impact of Division III sports. During first year student orientation, when incoming students move into the dorms, or simply during the first weeks of the semester, administrators should target new students through marketing campaigns to leverage the heightened levels of team identification upon arrival. Moreover, sporting events on campus might be used to build relationships between incoming students during the early weeks of the semester.

Second, as campus administrators and decision-makers struggle with financial decisions, our analysis shows that Division III athletics may be conceptualized as a tool to increase retention not only among student-athletes, but among non-athletes as well. Our results cannot confidently say that identifying with a sport team will increase retention, but theoretically the link between organizational identification and commitment is well-established (Ashforth \& Mael, 1989). Consequently, the economic value of Division III needs to include its potential impact on retaining students. Just as Eifling (2013) and Demirel (2013) noted the tuition benefits associated with Division III student-athletes, the value of sponsoring a Division III program may also include its effect on retention. Campus administrators are no doubt aware that dropouts and transfer decision often peak in the early weeks or months of a students' time on campus, using Division III athletics as a point of attachment and commonality between newcomers may very well lessen the burdens of adjusting to one's new place on campus.

Through this study, we aimed to spark a conversation about the social value of college sports on campuses outside of big-time intercollegiate athletics. Research on college sport should focus no merely on the most popular and commercial enterprises, but rather reflect the landscape of college sport setting based on the reality and alignment and participation. Division III represents the most popular intercollegiate setting for NCAA members, but the social impact of sports on campus has been largely 
ignored by academic research. And though researchers have examined a variety of other issues in the Division III setting, we suggest the impact of sports for non-athletes on campus remains mostly absent from the discourse. As the NCAA faces increasing scrutiny for myriad reasons, administrators need a better understanding of the benefits and deficiencies of all levels of intercollegiate sport to better plan for the future.

College sports on campus do not merely impact those student-athletes participating on the court or the field; college sports impact the entire study body and campus community. Even in the Division III setting, college sports are able to serve as the front porch of the university - though in a different way than their big-time college sport peers. While the front porch in big-time college sports may influence institutional visibility, notoriety, or admission rates, the front porch at the lower levels of college sports is more structurally designed to serve as an early point of attachment to the larger house and help students in their initial adjustment to the campus community.

\section{References}

Ashforth, B.E., \& Mael, F. (1989). Social identity theory and the organization. Academy of Management Review, 14, 20-39.

Anderson, B. (1983). Imagined communities. London: Verso.

Astin, A. (1984). Student involvement: A developmental theory of higher education. Journal of College Student Personnel, 25, 297-308.

Bass, J. R., Schaeperkoetter, C. C., \& Bunds, K. S. (2015). “The front porch": Examining the increasing interconnection of university and athletic department funding. ASHE Higher Education Report Monograph Series.

Bowen, W.G., \& Levin, S.A. (2003). Reclaiming the game: College sports and educational values. Princeton, NJ: Princeton University Press.

Carlson, B.D., Suter, T.A., \& Brown, T.J. (2008). Social versus psychological brand community: The role of psychological sense of brand community. Journal of Business Research, 61, 284-291.

Clopton, A.C. (2008). College sports on campus: Uncovering the link between fan identification and sense of community. International Journal of Sport Management, 9, 1-20.

Clopton, A.C., \& Finch, B.L. (2008). Are college students "bowling alone?" Examining the contribution of team identification to the social capital of college students. Journal of Sport Behavior, 33, 377-402.

Clotfelter, C.T. (2011). Big-time sports in American universities. New York, NY: Oxford University Press.

Cooper, C.G., \& Weight, E.A. (2012). Maximizing organizational effectiveness: NCAA Division III administrator core values and departmental culturization. Journal of Issues in Intercollegiate Athletics, 5, 339-353.

Crisp, G., Baker, V.L., Griffin, K.A., Lunsford, L.G., \& Pifer, M.J. (2017). Mentoring undergraduate students. ASHE Higher Education Report, 43, 7-103.

Demirel, E. (2013, October 1). The D-III revolution: How America's most violent game may be saving liberal arts colleges. Retrieved from http://www.sbnation.com/longform/2013/10/1/4786810/diii-football-revolution

Eifling, S. (2013, October 2). How Division III colleges profit from football no one watches. Retrieved from http://deadspin.com/how-division-iii-colleges-profit-from-football-noone-w-1440369611

Fink, J.S., Pastore, D.L., \& Riemer, H.A. (2003). Managing employee diversity: Perceived practices and organisational outcomes in NCAA Division III athletic departments. Sport Management Review, 6, 147-168. 
Fulks, D.L. (2015). Revenues and expenses: 2004-2012 NCAA Division III intercollegiate athletics programs report. Indianapolis, IN: National College Athletic Association.

Goff, B. (2000). Effects of university athletics on the university: A review and extension of empirical assessment. Journal of Sport Management, 14, 85-104.

Heere, B., \& James, J.D. (2007). Stepping outside the lines: Developing a multi-dimensional scale based on social identity theory. Sport Management Review, 10, 69-91.

Heere, B., \& Katz, M. (2014). Still undefeated: Exploring the dimensions of team identity among fans of a new college football team. Journal of Applied Sport Management, 6, 25-42.

Heere, B., Walker, M., Yoshida, M., Ko, Y.J., Jordan, J., \& James, J.D. (2011). Brand community development through associated communities: Grounding community measurement within social identity theory. Journal of Marketing Theory and Practice, 19, 407-422.

Hobsbawn, E.J. (1990). Nations and nationalism since 1870. Cambridge: Cambridge University Press.

Hossler, D., Shapiro, D., Dunbar, A., Ziskin, M., Chen, J., Zerquera, D., \& Torres, V. (2012). Transfer and mobility: A national view of pre-degree student movement in postsecondary institutions. Signature Report 2. National Student Clearinghouse.

Huttenlocher, J., Haight, W., Bryk, A., Seltzer, M., \& Lyons, T. (1991). Early vocabulary growth: Relation to language input and gender. Developmental Psychology, 27, 236-248.

Katz, M., \& Clopton, A.C. (2014). Town \& gown...\& jerseys? NCAA Division III athletics as social anchors. Journal of Issues in Intercollegiate Athletics, 7, 285-306.

Katz, M., \& Heere, B. (2016). New team, new fans: A longitudinal examination of team identification as a driver of university identification. Journal of Sport Management, 30, 135-148.

Katz, M., Pfleegor, A.G., Schaeperkoetter, C., \& Bass, J.B. (2015). Factors for success in NCAA Division III Athletics. Journal of Issues in Intercollegiate Athletics, 8, 102-122.

Katz, M., \& Seifried, C.S. (2014). And then there were three: The NCAA's struggle for reorganization and the emergence of Division III athletics. Sport History Review, 45, $145-170$.

Lock, D., Funk, D.C., Doyle, J.P., \& McDonald, H. (2014). Examining the longitudinal structure, stability, and dimensional interrelationships of team identification. Journal of Sport Management, 28, 119-135.

Longman, J. (May 29, 2009). As costs of sports rise, students balk at fees. The New York Times.

Mangold, W.D., Bean, L., \& Adams, D. (2003). The impact of intercollegiate athletics on graduation rates among major NCAA Division I universities: Implications for college persistence theory and practice. The Journal of Higher Education, 74(5), 540-562.

Pascarella, E.T., \& Terenzini, P.T. (2005). How college affects students: A third decade of research. San Francisco, CA: Jossey-Bass.

Pope, D.G., \& Pope, J.C. (2009). The impact of sports success on the quantity and quality of student applications. Southern Economic Journal, 75, 705-780.

Pope, D.G., \& Pope, J.C. (2014). Understanding college application decisions: Why college sports success matters. Journal of Sports Economics, 15, 107-131.

Rausch, J.L., \& Hamilton, M.W. (2006). Goals and distractions: Explanations of early attrition from traditional university freshman. Qualitative Report, 11, 317-334.

Robinson, C. (2010). Marketing intercollegiate athletics at the NCAA Division III level. Journal of Applied Sport Management, 2, 1-4.

Schaeperkoetter, C.C., Bass, J.R., \& Gordon, B.S. (2015). Student-athlete school selection: A family systems theory approach. Journal of Intercollegiate Sport, 8, 266-286.

Shulman, J.L., \& Bowen, W.G. (2002). The game of life: College sports and educational values. Princeton, NJ: Princeton University Press.

Singer, J.D., \& Willet, J.B. (2003). Applied longitudinal data analysis: Modeling change and event occurrence. New York, NY: Oxford University Press. 
Smith, J., Williams, D., Soebbing, B.P., \& Washington, M. (2013). The influence of a university's social identity on changing athletic affiliations. Journal of Issues in Intercollegiate Athletics, 6, 22-40.

Sparvero, E.S., \& Warner, S. (2013). The price of winning and the impact of the NCAA community. Journal of Intercollegiate Sport, 6, 120-142.

Sperber, M. (2000). Beer and circus: How big-time college sports is crippling undergraduate education. New York, NY: Holt Paperback.

Strayhorn, T.L. (2012). College students' sense of belonging: A key to educational success for all students. New York, NY: Routledge.

Svartberg, M., Seltzer, M.H., Stiles, T.C., \& Khoo, S.T. (1995). Symptom improvement and its temporal course in short-term dynamic psychotherapy: A growth curve analysis. The Journal of Nervous and Mental Disease, 183, 242-248. PubMed

Tinto, V. (1987). Leaving college: Rethinking the causes and cures of student attrition. Chicago, IL: University of Chicago Press.

Tivnan, T. (1980). Improvements in performance on cognitive tasks: The acquisition of new skills by elementary school children. Unpublished doctoral dissertation. Harvard University, Graduate School of Education.

Wann, D.L., \& Robinson, T.N., III. (2002). The relationship between sport fan identification and integration into and perceptions of a university. International Sports Journal, 6, 36-44.

Warner, S., Shapiro, S.L., Dixon, M.A., Ridinger, L.L., \& Harrison, S.B. (2011). The football factor: Shaping community on campus. Journal of Issues in Intercollegiate Athletics, 4, 236-256. 